\section{CASES OF UV-C EXPOSURE OF CUISINE EMPLOYEES IN SCHOOL MEALS}

${ }^{1}$ Soungcheoul Lee*, 'Jeongok Kong, 'Hyeonmi Lee, 'Jongwoo Kim, 1,2Jeongwan Koo. 'Gyeonggi Dongbu Workers' Health Centre; 'Department of Occupational and Environmental Medicine, Seoul St. Mary's Hospital, Catholic University of Korea

\subsection{6/oemed-2018-ICOHabstracts.963}

Introduction Since 2011, cuisine employees in one elementary school in Gyeonggi-do in Korea have complained of pain in eyes, neck and face. The manager and cuisine employees of the elementary school tried to find the cause but could not find it.

Finally, in February 2017, they asked the Gyeonggi Dongbu Workers' Health Centre in Korea to identify the cause of the symptoms of the cuisine employees.

The purpose of this study was to investigate the causes of work related symptoms of cuisine employees.

Methods In February 2017, an occupational and environmental medicine physician interviewed eight cuisine employees about symptoms, and In March 2017, a work environment evaluation team(industrial hygienists, occupational and environmental medicine physicians and nurses) visited the school meals to identify the cause of the symptoms.

Results Symptoms of cuisine employees were in the eyes and on the skin of the face and neck. Symptoms of the eyes were feeling of irritation, inflamed eye, eye watered, blurred, deteriorate eyesight, and Symptoms of the skin of the face and neck were (a relatively clear boundaries)skin flare, flakiness. In addition, all cuisine employees appealed lethargy, depression, extreme stress.

These symptoms occurred on the day of the dishwashing. The work process of the day was as follows. Check food ingredients and preprocessing (food ingredients cleaning) (from 7:30 am to 9:00 am), cooking and distribution(form 9:00 am to $1: 30 \mathrm{pm}$ ) and dishwashing (from $1: 30 \mathrm{pm}$ to $3: 30 \mathrm{pm}$ )

As a result of the field survey, there was no problem with the detergent, the ventilation system, the high temperature dryer for drying dishes and even the UV disinfection system.

However, The ultraviolet lamp used in vector system was UV-C, not UV-A. As a result of the measurement ultraviolet radiation, the degree of ultraviolet radiation exposure at the position where workers work is very high $\left(120 / \mathrm{cm}^{2} \sim 150 /\right.$ $\mathrm{cm}^{2}$ ). This amount of exposure was such that the exposure time should not exceed $30 \mathrm{~s}$. The Vector system was installed in the pretreatment room from 2011.

As a result, the cuisine employees were exposed to UV-C on the vector system in the morning('check food ingredients and preprocessing' (from 7:30 am to 9:00 am)) and symptoms appeared in the afternoon.

Conclusion The first step taken was to remove the UV-C lamp form the vector system. After removing the UV-C lamp, the symptoms of the cuisine employees checked for up to 3 weeks, symptoms of most cuisine employees were improving.
However, some cuisine employees still complain of symptoms and we will continue to observe changes in symptoms.

\section{CROSS-SECTIONAL SURVEY OF NHS HEALTHCARE WORKERS REFERRED TO AN OH SERVICE: PREVALENCE OF INFORMAL CARER RESPONSIBILITY AND MEASUREMENT OF WELL-BEING}

Elizabeth McCarthy*, Elizabeth Murphy*. Newcastle OHS, The Newcastle upon Tyne NHS Hospitals Foundation Trust Regent Point, Regent Farm Road Gosforth Newcastle upon Tyne NE3 1 HD

\subsection{6/oemed-2018-ICOHabstracts.964}

Introduction An informal carer is somebody who provides unpaid support for a significant proportion of time to a person who may be ill, disabled, have mental health or substance misuse problems. ${ }^{1}$ The ageing population and demand for care is growing; this can effect employees, employers and the economy.

Aim To assess the prevalence of informal carers referred to the Occupational Health service of an NHS organisation and to evaluate the impact of being an informal carer on employee well-being using the Warwick-Edinburgh Mental Well-being Scale (WEMWBS).

Method Cross-sectional study on employees referred to Occupational Health (between February and July 2015). A web based questionnaire was completed. A validated well-being score (WEMWBS) was used to assess mental well-being.

Results 547 questionnaires were completed; a response rate of $36.6 \%$. The prevalence of informal carers was $23.77 \%$. Most informal carers were aged over 36 years, were more likely to be female and to work part-time. Informal carers had more self-reported long-term sickness absence than non-carers.

Informal carers scored lower on the WEMWBS well-being score than non-carers (45.4 compared to 48.0). Both noncarers and informal carers scored lower than the Scottish population WEMWBS mean score (50.7).

Most informal carer respondents carried out their caring role once a day or more often $(51.4 \%)$; the majority of this group worked full time. Informal carers subjectively felt their caring role impacted on well-being.

Conclusion The prevalence of informal carers in this study is higher than published figures. Informal carers were found to have a lower mean mental well-being score than non-carers, which is in keeping with published literature. The results of the study should be shared with key stakeholders in the organisation to raise the profile of informal carers and improve available support.

\section{REFERENCE}

1. Department of Health. Carers at the heart of the 21st century, families and communities 2008. Available at https://www.gov.uk/government/uploads/system/ uploads/attachment_data/file/136492/carers_at_the_heart_of_21_century_families.pdf (accessed: 25 November 2016). 